\begin{tabular}{|c|c|c|c|}
\hline Fat. & I & $\begin{array}{l}\text { Methods. } \\
\text { II }\end{array}$ & III \\
\hline oil $\ldots \ldots \ldots \ldots \ldots \ldots$ & $20 \mathrm{I}$ & 203.8 & 202.8 \\
\hline Corn oil $\ldots \ldots \ldots \ldots \ldots \ldots, \ldots \ldots \ldots$ & I92 & 193.2 & I93.4 \\
\hline Rosin oil $\ldots \ldots \ldots \ldots \ldots \ldots \ldots \ldots \ldots \ldots$ & 76.9 & $77 \cdot 4$ & 75.1 \\
\hline 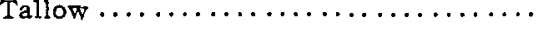 & 196.5 & I96.9 & 196.5 \\
\hline
\end{tabular}

Each figure represents the average of two determinations.

The number given under method $I$ is the saponification number obtained when the oil was saponified with alcoholic potash only.

The number given under method II is the saponification number obtained when the oil was saponified with alcoholic potash and benzene.

The number given under method III is the saponification number of the oil obtained when it was mixed with an equal quantity or more of mineral oil, and the saponification number determined by means of alcoholic potash and benzene.

In mixing the oils they were weighed into the Erlenmeyer flask, warmed on the steam bath and shaken to mix as thoroughly as possible. The amount of alkali used up by the mineral oil was separately determined and allowance made for it.

The oils were saponified for one-half hour in each case.

\title{
THE FULLER'S EARTH TEST FOR CARAMEL IN VINEGAR.
}

\author{
BY W. L. DUbors. \\ Received Oct. 27, I906
}

The fuller's earth test for caramel appears in a number of publications covering methods for food analysis, and has been used quite generally for the detection of added caramel in cider vinegar. In some cases the method has been published with no statement of the precautions necessary to its manipulation, nor the severe limitations to which it is subject. In order to investigate these points and if possible prescribe conditions under which it could be applied with certainty, the work described in this article was undertaken.

Fifty samples of pure cider vinegar were obtained from farmers in Pennsylvania through the agents of Dr. B. H. Warren. Of these eleven were selected, differing as much as possible in physical appearance. Five vinegars made by the author in 1905 were also included in the experiment.

Samples of fuller's earth were procured from several houses and from a number of food chemists, the purpose for which the samples were desired being stated. The method was applied as follows :

Fifty cubic centimeters of vinegar and $25 \mathrm{~g}$. of fuller's earth were measured out into a $250 \mathrm{cc}$. beaker, stirred thoroughly and allowed to stand one-half hour. The mixture was then filtered through a dry folded filter, and the color of the filtrate compared with that of the untreated vinegar, filtered in the same way. Color comparisons were made in a Duboscq colorimeter. In the table below the results are expressed as 
per cent. of the total color removed by fuller's earth. The last five vinegars in the table were made by the writer.

\begin{tabular}{|c|c|c|c|c|c|c|c|c|c|}
\hline & & $E R$ & $C E$ & $\mathrm{R}$ & IOVED & BY & $R^{\prime} R^{\prime} S$ & EAR & \\
\hline & 15653 & 15664 & 17038 & 17039 & $I 7040$ & 17042 & 27043 & 17045 & 17080 \\
\hline $\begin{array}{c}\text { Seria: } \\
\text { Number of } \\
\text { vinegar }\end{array}$ & 苛 & 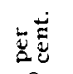 & ڤ⿱艹 & 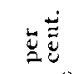 & 吾 & 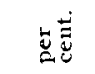 & $\bar{\Xi}$ & 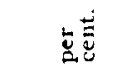 & 范 \\
\hline I 7046 & 29.6 & $3^{8.0}$ & 24.0 & 44.8 & 28.0 & 31.2 & 18.4 & 50.0 & .. \\
\hline 17047 & 41.9 & 46.8 & 48.0 & 60.2 & 42.0 & 42.0 & 43.2 & 50.0 & . \\
\hline I 7048 & 34.0 & 20.0 & 30.0 & 44.0 & 22.2 & 25.0 & 25.0 & 4.2 & $\cdots$ \\
\hline 17049 & $\cdots$ & 31.6 & $\infty .0$ & 20.0 & $\infty .0$ & 20.0 & 00.0 & 00.0 & 00.0 \\
\hline 17050 & 20.0 & $3^{6.7}$ & 00.0 & 4.0 & 00.0 & 23.3 & 00.0 & 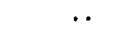 & 48.3 \\
\hline I 7055 & oo.o & 00.0 & 7.7 & 52.0 & 20.0 & $3^{6.8}$ & 33.3 & 40.5 & $\cdots$ \\
\hline 17056 & 70.8 & 68.0 & 67.9 & 70.0 & 66.0 & 60.7 & 66.6 & 66.6 & 71.4 \\
\hline I 7057 & . & 28.0 & 27.2 & 32.0 & I 2.0 & 20.0 & 00.0 & 30.0 & $45 \cdot 5$ \\
\hline I $705^{8}$ & .. & 40.0 & 25.0 & 25.0 & 24.0 & 36.0 & 4.0 & 20.0 & 71.9 \\
\hline 17059 & .. & 44.0 & 20.0 & 30.0 & 4.0 & 10.0 & 25.0 & 23. I & $\ldots$ \\
\hline 17060 & 56.2 & 63.1 & 65.0 & 66.6 & 63.1 & 53.3 & $6 \hat{3} . I$ & 67.6 & \\
\hline I 75 I 2 & .. & . & . & 57.9 & 42.9 & 00.0 & 35.9 & 63.4 & .. \\
\hline 17513 & .. & . & . & 43.4 & 24.7 & 16.7 & 21.8 & 66.6 & \\
\hline I 7514 & . & .. & . & 4 r. 2 & I 3.0 & 00.0 & 00.0 & 50.0 & $\cdots$ \\
\hline I 7515 & . & . & . & 37.5 & 00.0 & $\cdots$ & I I.O & . & . \\
\hline 17516 & .. & .. & .. & 41.2 & 37.5 & $3^{8.9}$ & 32.5 & 57.6 & . \\
\hline
\end{tabular}

\section{DISCUSSION OF RESULTS.}

The color removed from pure cider vinegar by fuller's earth varies according to the figures in the table, from none to seventy-two per cent. No one sample of fuller's earth can be selected from the above as giving uniform results. For instance, Nos. 15663 and 15664 remove no color from vinegar No. I7055, thereby indicating it as pure, while from vinegar No. 17056 , just as pure as the first indicated, 7 I per cent. and 68 per cent. respectively of color are removed. Vinegar No. i 7050 would be indicated as pure by treatment with earths Nos. I7038, 17040 and I7043, while its case would be made doubtful by earth No. 15663 and condemned by 15664. Again, earths Nos. I7038, I7040 and I7043, which give uniform results on vinegar No. I 7050 and comparable results on several others, are at wide variance on vinegar No. I7057. Earth No. I7080 is one received from a chemist who uses this test and declares it reliable if 25 to 30 per cent. be allowed for the color which fuller's earth will remove from pure vinegar. As shown in the table it removes from one sample of pure cider viuegar no color at all, while taking out as much as 72 per cent. of color from another sample. There seems to be no uniformity in the data and it is impossible to select any one of the fuller's earths tried which could be relied upon to give truthful results. In the writer's estimation the method is unreliable and should only be used as a preliminary test. If no color or only a small percentage of color is removed, the analyst is reasonably safe in pronouncing the sample pure. On the other hand, if all the color disappears, he is equally secure in declaring caramel present. But for the large number of vinegars which lose from 25 to 75 per cent. of their color when treated with fuller's earth, the data obtained by this test are not 
final, and it is necessary to subject the vinegar to further treatment before a conclusion regarding the presence of caramel can be reached.

Bureau of Chemistry, U. S. Dept. of. Agr .

[CONTribution From the ChEMICAL LABORATORY OF Harvard COLLEge.]

\section{HYDRAZONES OF AROMATIC HYDROXYKETONES. ALKALI- INSOLUBLE PHENOLS.}

\section{PRELIMINARY PAPER. \\ BY HENRY A. TORREY AND H. B. KIPPER. \\ Received November 12, 1906.}

The study of the action of phenylhydrazine upon aceto- and benzophenones carrying an hydroxyl group in the ortho position to the side chain seemed to us a reaction of some interest, since the possibility suggested itself that, under some conditions, in addition to the attack on the ketone group the hydroxyl of the ring might be made to react with the imide hydrogen thus forming a five-membered ring, calling to mind the action of phenylhydrazine on acetacetic ester.

Although thus far we have been unable to obtain such a secondary condensation, the hydroxyl group in the ortho position is affected in its properties by the formation of the hydrazones, since though these products supposably contain a free hydroxyl group they are insoluble in alkalies. Other examples of substances containing the hydroxyl group which are insoluble or difficultly soluble in alkalies are not entirely wanting. M. Rogow ${ }^{1}$ has prepared some phenols which are insoluble in alkalies; he obtained for instance, a compound by the action of naphthylamine on vanillin which shows this property. In his paper he cites similar cases discovered by other observers, among them the case of chief interest to us is the observation by $O$. Anselmino that the phenylhydrazone of homosalicylaldehyde is insoluble in aqueous alkalies.

The hydrazones which we have chiefly studied are those of dihydroxyaceto- and benzophenones, such as resacetophenone, dibenzoresorcinol and dibenzohydroquinone. The hydrazone $e^{3}$ of resacetophenone $e^{4}$ made by the action of phenylhydrazine on resacetophenone, is, as would naturally be expected soluble in alkalies, while paeonol, the monomethyl ether of resacetophenone, in which the only free hydroxyl group is ortho to the keto side chain,

1 J. pr. Chem. 2, 72, 315.

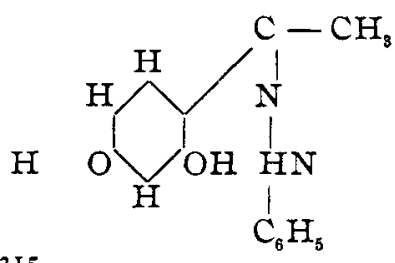

2 Ber. 35, 4099 .

${ }^{3}$ Ann. chim. pharm. 7,276 . B1. 36, I54.

4 J. pr. Chem. 2, 23, 147, 537. 